To be published in Small Specimen Test Techniques, ASTM STP 1329, held in New Orleans, January 13-14, 1997.

$$
\text { CONF-970124-- }
$$

\title{
USE OF PRECRACKED CHARPY AND SMALLER SPECIMENS TO ESTABLISH THE MASTER CURVE
}

\author{
M. A. Sokolov, ${ }^{1}$ D. E. McCabe, ${ }^{1}$ \\ Y. A. Davidov, ${ }^{2}$ and R. K. Nanstad ${ }^{1}$ \\ Metals and Ceramics Division \\ $2 *$ OAK RIDGE NATIONAL LABORATORY \\ P.O. Box 2008 \\ Oak Ridge, TN 37831-6151
}

\section{Onin}

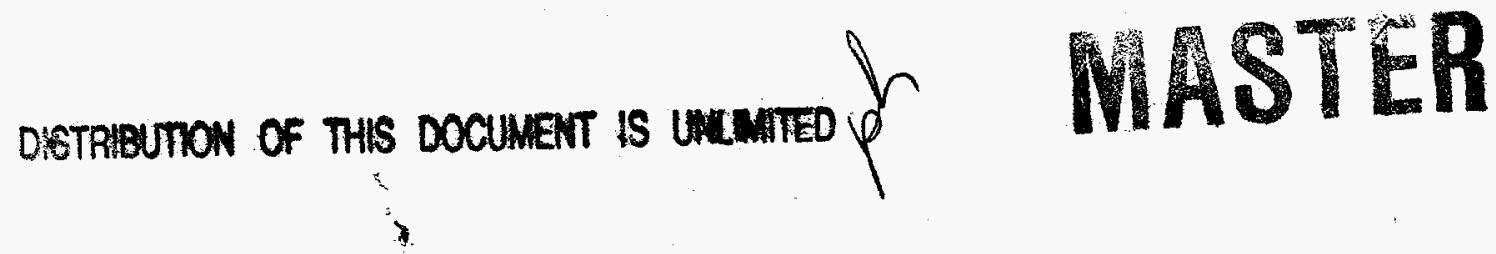

${ }^{1}$ Metals and Ceramics Division, Oak Ridge National Laboratory, P.O. Box 2008, Oak Ridge, TN 37831-6151, managed by Lockheed Martin Energy Research Corporation under contract DE-AC05-96OR22464 for the U.S. Department of Energy.

${ }^{2}$ On International Atomic Energy Agency Fellowship at Oak Ridge National Laboratory from the Institute of Metal Science, Sofia, Bulgaria. 


\section{DISCLAIMER}

This report was prepared as an account of work sponsored by an agency of the United States Government. Neither the United States Government nor any agency thereof, nor any of their employees, makes any warranty, express or implied, or assumes any legal liability or responsibility for the accuracy, completeness, or usefulness of any information, apparatus, product, or process disclosed, or represents that its use would not infringe privately owned rights. Reference herein to any specific commercial product, process, or service by trade name, trademark, manufacturer, or otherwise does not necessarily constitute or imply its endorsement, recommendation, or favoring by the United States Government or any agency thereof. The views and opinions of authors expressed herein do not necessarily state or reflect those of the United States Government or any agency thereof. 


\section{DISCLAIMER}

Portions of this document may be illegible electronic image products. Images are produced from the best available original document. 


\title{
M. A. Sokolov, ${ }^{1}$ D. E. McCabe, ${ }^{1}$ Y. A. Davidov, ${ }^{2}$ and R. K. Nanstad ${ }^{1}$ \\ USE OF PRECRACKED CHARPY AND SMALLER SPECIMENS TO ESTABLISH THE MASTER CURVE
}

REFERENCE: Sokolov, M. A., McCabe, D. E., Davidov, Y. A., and Nanstad, R. K., "Use of Precracked Charpy and Smaller Specimens to Establish the Master Curve," Small specimen Test Techniques, ASTM STP 1329, W. R. Corwin, S. T. Rosinski, and E. van Walle, Eds., American Society for Testing and Materials, 1997.

\begin{abstract}
ABSfíRACT: The current provisions used in the U.S. Code of Federal Regulations for the determination of the fracture toughness of reactor pressure vessel steels employs an assumption that there is a direct correlation between $\mathrm{K}_{\mathrm{fc}}$ lower-bound toughness and the Charpy V-notch transition curve. Such correlations are subject to scatter from both approaches which weakens the reliability of fracture mechanics-based analyses. In this study, precracked Charpy and smaller size specimens are used in three-point static bend testing to develop fracture mechanics based $\mathrm{K}_{\mathrm{fc}}$ values. The testing is performed under carefully controlled conditions such that the values can be used to predict the fracture toughness performance of large specimens. The concept of a universal transition curve (master curve) is applied. Data scatter that is characteristic of commercial grade steels and their weldments is handled by Weibull statistical modeling. The master curve is developed to describe the median $\mathrm{K}_{\mathrm{Jc}}$ fracture toughness for $1 \mathrm{~T}$ size compact specimens. Size effects are modeled using weakest-link theory and are studied for different specimen geometries. It is shown that precracked Charpy specimens when tested within their confined validity limitsłfollow the weakest-link size-adjustment trend and predict the fracture toughness of larger specimens. Specimens of smaller than Charpy sizes $(5 \mathrm{~mm}$ thick) exhibit some disparities in results relative to weakest-link size adjustment prediction suggesting that application of such adjustment to very small specimens may have some limitations.
\end{abstract}

KEYWORDS: master curve, precracked Charpy, weakest-link theory, Weibull distribution, reactor pressure vessel, fracture toughness

'Metals and Ceramics Division, Oak Ridge National Laboratory, P.O. Box 2008, Oak Ridge, TN 37831-6151, managed by Lockheed Martin Energy Research Corp. under Contract DE-AC05-960R22464 for the U.S. Department of Energy.

${ }^{2}$ On International Atomic Energy Agency Fellowship at Oak Ridge National Laboratory from the Institute of Metal Science, Sofia, Bulgaria. 


\section{INTRODUCTION}

The American Society of Mechanical Engineers (ASME) $\mathrm{K}_{\mathrm{Ic}}$ curve is based upon data acquired by testing large specimens of unirradiated reactor pressure vessel (RPV) steels and weld metals that satisfy the validity requirements of the American Society for Testing and Materials (ASTM) Standard Test Method for Plane-Strain Fracture Toughness of Metallic Materials (E 399-90). Currently, the provisions for determination of the upward temperature shift of the ASME $\mathrm{K}_{\mathrm{lc}}$ curve due to irradiation are based on the Charpy V-notch (CVN) 41-J shift, and the shape of the fracture toughness curve is assumed to not change as a consequence of irradiation. The main reason for such assumptions was that it was not practical to generate the equivalent linear-elastic $K_{\mathrm{Ic}}$ data base for irradiated material in the transition region. In fact, the maximum size of compact specimens for irradiation studies is limited to $4 \mathrm{~T}(101.6 \mathrm{~mm})$ simply due to throughthickness fluence gradients.

In this study, precracked CVN (PCVN) and smaller specimens were used to characterize the fracture toughness of RPV steel in the transition region by means of three-point slow bending. The PCVN specimen as well as any fracture toughness specimen which could be made out of the broken halves of standard CVN specimens would have exceptional utility for reactor pressure vessels. The CVN specimen is the most commonly used specimen geometry in surveillance programs. Precracking and testing of irradiated Charpy surveillance specimens would allow one to determine and monitor directly actual fracture toughness of an irradiated vessel instead of requiring indirect predictions using correlations established with impact data.

However, with testing of small specimens in the transition region, some amount of local crack tip plasticity is unavoidable and fracture toughness up to cleavage instability is calculated in terms of size-dependent elastic-plastic $\mathrm{K}_{\mathrm{Jc}}$ values. Therefore, a statistical size correction based upon weakest-link theory has been proposed [1]. Data scatter that is characteristic of commercial grade steels and their weldments is handled by Weibull statistical modeling and the concept of a universal shape curve (master curve) is applied to characterize fracture toughness in the transition region. The master curve is developed to describe the median $\mathrm{K}_{\mathrm{Jc}}$ fracture toughness for $1 \mathrm{~T}$ size compact specimens. Thus, the ability of the PCVN and some smaller size specimens to establish the master curve for large compact specimens will be examined in this paper.

\section{ANALYSIS PROCEDURE}

The analysis procedure is based on fitting replicate fracture toughness data generated at a fixed temperature to a three-parameter Weibull cumulative distribution function. It was determined [2], at least for RPV steels, that among these three parameters, the shape parameter (Weibull slope) is equal to 4 and the location parameter, $\mathrm{K}_{\min }$, is about $20 \mathrm{MPa} / \mathrm{m}$. Fixing the slope $\mathrm{b}=4$ and $\mathrm{K}_{\min }=20$ gives the Weibull cumulative probability distribution function as: 


$$
P_{f}=1-\exp \left[-\left(\frac{K_{c}-20}{K_{o}-20}\right)^{4}\right]
$$

where $P_{f}$ is the cumulative fracture probability for $K \leq K_{\mathrm{Ic}}$ and $\mathrm{K}_{\mathrm{o}}$ is a specimen thickness and temperature-dependent scale parameter. Thus, only the scale parameter, $\mathrm{K}_{\text {o }}$, needs to be determined. As a consequence, only a few replicate tests are needed to obtain this parameter with good accuracy. The proposed ASTM practice [3] requires at least six replicated tests. The procedure employs the maximum likelihood concept regarded as the most accurate method of obtaining $\mathrm{K}_{\mathrm{o}}$ when there are so few replicate tests:

$$
\therefore \quad \mathrm{K}_{\mathrm{o}}=\left[\frac{\sum_{\mathrm{i}=1}^{N}\left(\mathrm{~K}_{\mathrm{J}(\mathrm{i})}-20\right)^{4}}{N-1+\ln 2}\right]^{1 / 4}+20, \mathrm{MPa} \sqrt{\mathrm{m}} \text {, }
$$

where $\mathrm{K}_{\mathrm{Jc}(i)}$ represents each datum obtained at the given test temperature. The term $\mathrm{N}$ is the total number of replicate data at that test temperature. Occasionally with the testing of small specimens, a data set may contain $\mathrm{K}_{\mathrm{Jc}}$ values which exceed a constraint limit, and, in such cases, Eq. (2) is modified to handle censored (invalid) data. The test specimen capacity currently set in Ref. [3] is calculated using the following:

$$
\mathrm{K}_{\mathrm{Jc} \text { (limit) }}=\left(\frac{\mathrm{E} \mathrm{b}_{\mathrm{o}} \sigma_{\mathrm{y}}}{30}\right)^{1 / 2}, \mathrm{MPa} \sqrt{\mathrm{m}}
$$

where $E$ is elastic modulus, $b_{o}$ is the initial remaining ligament dimension, and $\sigma_{y}$ is the yield strength. According to the proposed ASTM Draft Standard [3], the invalid data point is censored and assigned the $\mathrm{K}_{\mathrm{Jc} \text { (imini) }}$ toughness value. Then, the $\mathrm{K}_{\mathrm{o}}$ is determined by:

$$
K_{0}=\left[\frac{\sum_{i=1}^{N}\left(K_{J q(i)}-20\right)^{4}}{r-1+\ln 2}\right]^{1 / 4}+20, M P a \sqrt{m} \text {, }
$$

where $r$ is the number of valid data and $\mathrm{N}$ is the total number of valid and invalid $\mathrm{K}_{\mathrm{Jc}}$ values. This procedure is described in Ref. [3] and requires at least six valid data points to proceed.

For small specimen applications, size adjustment is a key point in this analysis procedure. Weakest-link theory is used [1] to explain statistical specimen size effects so 
that data, for example, equivalent to that for a $1 \mathrm{~T}$ size specimen, $\mathrm{K}_{\mathrm{Jc}(1 \mathrm{~T})}$, can be calculated from data measured with specimens of different sizes, $\mathrm{K}_{\mathrm{Jc}(\mathrm{xT})}$ :

$$
K_{J c(1 T)}=20+\left[K_{J c(x T)}-20\right]\left[\frac{B_{(x T)}}{B_{(1 T)}}\right]^{1 / 4}, M P a \sqrt{m},
$$

where $B_{(x I)}$ and $B_{(1)}$ are the test specimen and $1 T$ specimen thicknesses, respectively. Statistical size adjustment is based on the fact that cleavage fracture in the transition range is initiated by small microstructural defects that are always present in commercially produced RPV steels. Therefore, the thicker the specimen being tested, the higher the probability of encountering a trigger point of a critical size that is situated within the volume of material loaded to a critical stress state along the crack tip front. As a result, large specimens will display lower fracture toughness than specimens of smaller thickness. Equation (5) is the mathematical expression for these statistical effects. Finally, knowing all of the parameters of the distribution allows one to determine the median $\mathrm{K}_{\mathrm{jc}}$ toughness, $\mathrm{K}_{\mathrm{Ic}(\text { med) }}$ (the $\mathrm{K}_{\mathrm{jc}}$ value at $\mathrm{P}_{\mathrm{f}}=0.5$ ), for a specimen of chosen reference size, usually a $1 \mathrm{~T}$ $\mathrm{C}(\mathrm{T})$, at a given temperature.

Therefore, the current procedure provides a tool to describe the scatter of fracture toughness data in the transition region and to determine the median $\mathrm{K}_{\mathrm{Jc}}(1 \mathrm{~T})$ value by means of performing a few replicate tests. However, the application of this procedure to small specimens has some limitations. On the high-temperature side, small specimens are limited by specimen capacity to maintain constraint. According to Eq. (3), the remaining ligament size, $b_{0}$, is a critical parameter to satisfy the constraint limit for a given material. As the lower-shelf toughness at low temperatures is approached, Eq. (3) becomes inapplicable because the statistical size effects diminish and the initiation criterion is no longer dominant. Fracture becomes more propagation-controlled. This means that the test temperature range for small specimens is quite narrow in order to provide data acceptable for the current analysis procedure.

For structural ferritic steels, however, $\mathrm{K}_{\mathrm{Jc}(\mathrm{med})}$ values tend to form transition temperature curves of the same universal shape which is known now as the "master curve." The master curve of $\mathrm{K}_{\mathrm{JC}(\text { med })}$ for $1 \mathrm{~T}$ size specimens in the transition region is described by:

$$
\mathrm{K}_{\mathrm{Jc}(\mathrm{med})} \stackrel{\mathrm{IT}}{=}=30+70 \exp \left[0.019\left(\mathrm{~T}-\mathrm{T}_{100}\right)\right], \mathrm{MPa} \sqrt{\mathrm{m}}
$$

where $T_{100}$ is the reference temperature at which $\mathrm{K}_{\mathrm{Jc}(\mathrm{med})}{ }^{1 \mathrm{~T}}$ is $100 \mathrm{MPa} \sqrt{\mathrm{m}}$. The lower $(0.05)$ and upper (0.95) tolerance bounds are calculated using the following [3]:

$$
\mathrm{K}_{\mathrm{Ic}(0.95)}=34.6+102.2 \exp \left[0.019\left(\mathrm{~T}-\mathrm{T}_{100}\right)\right], \mathrm{MPa} \sqrt{\mathrm{m}}
$$




$$
\mathrm{K}_{\mathrm{Jq}(0.05)}=25.4+37.8 \exp \left[0.019\left(\mathrm{~T}-\mathrm{T}_{100}\right)\right] . \mathrm{MPa} \sqrt{\mathrm{m}} .
$$

Thus, having the temperature dependence of fracture toughness defined by Eq. (6) permits obtaining a value of $\mathrm{K}_{\mathrm{Jd}}{ }_{\mathrm{IT}} \mathrm{T}$ from PCVN type specimens at one temperature and then estimating the whole transition region curve by means of the master curve.

\section{MATERIAL AND SPECIMENS}

Three types of specimens were tested in the present study. The first type is the standard full-size Charpy specimen with dimensions of $10 \times 10 \times 55 \mathrm{~mm}$. The second type was made by thin-wire electrodischarge machine cutting along the axes of the full-size specimen. This specimen is $4.8 \mathrm{~mm}$ thick, $10 \mathrm{~mm}$ wide, and $55 \mathrm{~mm}$ long. Although this type of specimen is half as thick as a full-size specimen, it has the same remaining ligament size, which is the key size parameter in the constraint limit equation [Eq. (3)]. The third type of specimen was made from the broken half of a full-size specimen, has a $4.8 \times 4.8 \mathrm{~mm}$ cross section, and is about $27 \mathrm{~mm}$ long. The latter two types of specimens may be useful when the number of standard specimens is too limited for a good material evaluation, which is often the case in plant life extension and annealing evaluations. All specimens were fatigue precracked to an a/W ratio of about 0.5 and tested in slow three-point bending. Load versus load-point displacement was measured. Both the $10 \times 10 \times 55$ and $4.8 \times 10 \times 55 \mathrm{~mm}$ specimens were tested with the span of $40 \mathrm{~mm}$, while the $4.8 \times 4.8 \times 27 \mathrm{~mm}$ specimens were tested with a 20 -mm span. All 4.8-mm-thick specimens were $20 \%$ side-grooved. The standard size $\mathrm{CVN}$ specimens were tested without side grooves.

The ASTM A:533 grade B class 1 plate, designated Heavy-Section Steel Technology (HSST) Program Plate 02, was selected for the present study. The selection of this plate was based on the existence of an extensive fracture toughness database for Plate 02 accumulated by testing large specimens. Westinghouse tested 70 specimens of different sizes up to 11T thickness to establishing what is now known as the ASME lower-bound $\mathrm{K}_{\mathrm{Ic}}$ curve [4]. Additionally, $251 \mathrm{~T}$ compact specimens of the plate were subsequently tested in the transition range as a part of the HSST Program performed at Oak Ridge National Laboratory (ORNL) [5].

Initially, these $1 \mathrm{~T}$ data were analyzed by the master curve procedure and the reference fracture toughness transition temperature, $T_{100}$, was determined to be $-23^{\circ} \mathrm{C}[6]$. Based on this value of $\mathrm{T}_{100}$, most of the tests were performed at $-50^{\circ} \mathrm{C}$. At the temperature of $-50^{\circ} \mathrm{C}$, the value of $\mathrm{K}_{\mathrm{Jc(me)})}$ from $1 \mathrm{~T}$ compact specimens is $71.9 \mathrm{MPa} \sqrt{\mathrm{m}}$, which for $5-\mathrm{mm}$-thick specimens converts to about $100 \mathrm{MPa} / \mathrm{m}$, based on the estimation by Eq. (5). The draft standard [3] recommends performing tests at a temperature close to that at which median $\mathrm{K}_{\mathrm{fc}}$ values will be about $100 \mathrm{MPa} \sqrt{\mathrm{m}}$. Seven 
$10 \times 10 \times 55$, eight $4.8 \times 10 \times 55$, and twelve $4.8 \times 4.8 \times 27 \mathrm{~mm}$ specimens were tested at $-50^{\circ} \mathrm{C}$. Additionally, seven $10 \times 10 \times 55$ and eight $4.8 \times 10 \times 55 \mathrm{~mm}$ specimens were tested at $-30^{\circ} \mathrm{C}$.

\section{FULL-SIZE PRECRACKED CHARPY DATA}

Test data for all specimens studied are summarized in Table 1. For the full-size PCVN specimens, the reference transition temperatures, $T_{100}$, as determined by rearranging Eq. (6), were -23 and $-26^{\circ} \mathrm{C}$ after testing at -50 and $-30^{\circ} \mathrm{C}$, respectively. The difference between the two values is only $3^{\circ} \mathrm{C}$, which indicates that median toughness values determined by PCVN specimens fit very well to the shape of the master curve. The average of these two values, $-25^{\circ} \mathrm{C}$, is used as the reference fracture toughness temperature determined by testing of PCVN specimens in the following evaluations of HSST Plate 02 properties.

Data from PCVN specimens are in very good agreement with $1 \mathrm{~T}$ compact $\mathbf{K}_{\mathbf{k}}$ data $\{\xi\}\left(\mathrm{T}_{100}=-23^{\circ} \mathrm{C}\right)$. However, a question remains regarding the relevance of properties evaluated by the "master curve" procedure to the ASME lower-bound $\mathrm{K}_{\mathrm{f}}$ curve. The ASME $\mathrm{K}_{\mathrm{Ic}}$ curve was constructed as a lower bound to its respective linear-elastic $\mathrm{K}_{\mathrm{Ic}}$ database for reactor pressure vessel steels [4] plotted as a function of test temperature $(T)$ normalized to a reference nil-ductility temperature, $R_{\mathrm{NDT}}$, namely, $\mathrm{T}-\mathrm{RT}_{\mathrm{NDT}}$. The $\mathrm{RT}_{\mathrm{NDT}}$ is derived from either drop-weight or CVN impact test results. The majority of the ASME database is represented by the HSST Plate 02. Obviously none of the $\mathrm{K}_{\mathrm{jc}}$ values from PCVN specimens reported in Table 1 could satisfy the validity requirements for linear-elastic $\mathrm{K}_{\mathrm{Ic}}$ stated in ASTM E 399-90. Valid $\mathrm{K}_{\mathrm{Ic}}$ data have for many years been regarded as necessary to define the lower bound of fracture toughness. Nevertheless, it was recently shown [7] that the Weibull distribution function models the scatter in the ASME $\mathrm{K}_{\mathrm{Ic}}$ data very well, while the temperature dependence is described by the master curve. Thus, the master curve evaluated by testing PCVN specimens will be compared to the linear-elastic $K_{\mathrm{rc}}$ data of HSST Plate 02 and then to all of the ASME $\mathrm{K}_{\mathrm{Ic}}$ database.

Figure 1 shows the fracture toughness $\mathrm{K}_{\mathrm{rc}}$ data for HSST Plate 02 derived by testing 70 specimens of different sizes up to $11 \mathrm{~T}$ thickness [4]. The statistical size adjustment by Eq. (5) is applied to convert the data to 1T size equivalence. Finally, the master curve and lower $5 \%$ tolerance bound by Eq. (8) evaluated from the testing of PCVN specimens $\left(\mathrm{T}_{100}=-25^{\circ} \mathrm{C}\right)$ are compared to these size-adjusted $\mathrm{K}_{\mathrm{Ic}}$ data on the same plot. To cover uncertainty in $\mathrm{T}_{100}$ due to testing only a few PCVN specimens, a margin, $\Delta \mathrm{T}_{100}=7^{\circ} \mathrm{C}$, is added to the tolerance bound. The procedure and details of the margin calculation are presented in Refs. [3] and [6]. Figure 2 shows that the master curve and the $5 \%$ margin-adjusted tolerance bound derived from testing several PCVN specimens represent very well the large $\mathrm{K}_{\mathrm{Ic}}$ database accumulated by testing of massive specimens.

Having success in describing the $\mathrm{K}_{\mathrm{Ic}}$ database by the master curve from PCVN specimens of the same material, the next step is to make a direct comparison between the 
Table 1. Results of three-point slow-bend specimen data analysis of HSST Plate 02

\begin{tabular}{|c|c|c|c|c|c|c|}
\hline $\begin{array}{c}\text { Specimen } \\
\text { size } \\
(\mathrm{mm})\end{array}$ & $\begin{array}{c}\mathrm{T}_{\text {tex }} \\
\left({ }^{\circ} \mathrm{C}\right)\end{array}$ & $\begin{array}{c}\text { Number } \\
\text { of data } \\
\text { points } \\
(\mathrm{N})\end{array}$ & $\begin{array}{c}\text { Valid } \\
\text { data } \\
\text { points } \\
(\mathrm{r})\end{array}$ & $\begin{array}{c}\mathrm{K}_{\mathrm{o}} \\
(\mathrm{MPa} \vee \mathrm{m})\end{array}$ & $\begin{array}{c}\mathrm{K}_{\mathrm{Jc(med)}} \\
(\mathrm{MPa} \vee \mathrm{m})\end{array}$ & $\begin{array}{c}\mathrm{T}_{100} \\
\left({ }^{\circ} \mathrm{C}\right)\end{array}$ \\
\hline $10 \times 10 \times 55$ & -50 & 7 & 7 & 91.9 & 85.42 & -23 \\
$4.8 \times 10 \times 55$ & -50 & 8 & 8 & 81.1 & 75.8 & 1 \\
$4.8 \times 4.8 \times 27$ & -50 & 12 & 8 & 103.7 & 96.4 & -21 \\
$10 \times 10 \times 55$ & -30 & 8 & 7 & 122.9 & 114.6 & -26 \\
$4.8 \times 10 \times 55$ & -30 & 10 & 8 & 124.9 & 115.7 & -15 \\
\hline
\end{tabular}

3.

2

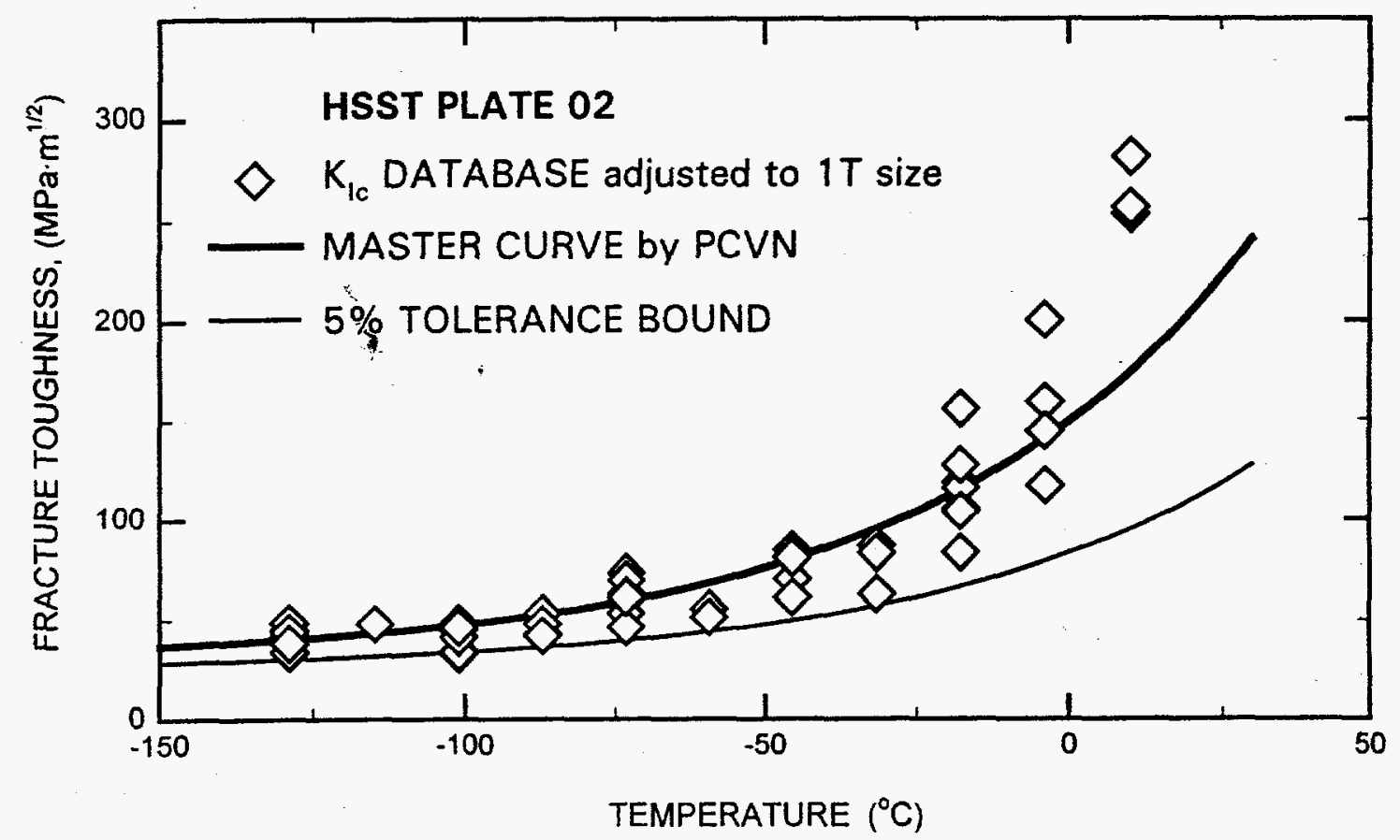

FIG. 1--Comparison of the HSST Plate 02 linear-elastic $\mathrm{K}_{\mathrm{Ic}}$ database relative to the master curve with $5 \%$ margin-adjusted tolerance bound curve derived by testing of several PCVN specimens. 
ASME lower bound curve and the 5\% margin-adjusted tolerance bound curve, see Fig. 2 . All $174 \mathrm{~K}_{\mathrm{lc}}$ data from the EPRI database have been reexamined and checked for accuracy in Ref. [8]; these data are also plotted in this figure. The top and right axes are in English units which is usual when relative temperature, $T-\mathbf{R T}_{\mathrm{NOT}}$, is expressed in ${ }^{\circ} \mathrm{F}$. The first ASME curve was manually constructed as the lower boundary to $\mathrm{K}_{\mathrm{tc}}$ values only in the normalized temperature range of $\mathrm{T}-\mathrm{RT}_{\mathrm{NDT}}$ from -100 to $+100^{\circ} \mathrm{F}$. More recently, the manually constructed representation has been replaced by the so-called EPRI equation (expressed in SI units):

$$
\mathrm{K}_{\mathrm{Ic}}=36.5+3.083 \exp \left[0.036\left(\mathrm{~T}-\mathrm{RT}_{\mathrm{NDT}}+55.6\right)\right] . \mathrm{MPa} \sqrt{\mathrm{m}} \text {. }
$$

For comparison, the $5 \%$ margin-adjusted tolerance bound curve derived from testing of PCVN specimens of HSST Plate 02 in the temperature coordinate normalized to $\mathrm{RT}_{\mathrm{NDT}}$, including the effect of $\Delta T_{100},{ }^{3}$ is equal to:

$$
\therefore \quad \mathrm{K}_{\mathrm{So}(0.05)}=25.4+37.8 \exp \left[0.019\left(\mathrm{~T}-\mathrm{RT}_{\mathrm{NDT}}\right)\right], \mathrm{MPa} \sqrt{\mathrm{m}} \text {. }
$$

In Fig. 2, Eqs. (9) and (10) are both plotted over the full temperature range of the $\mathrm{K}_{\mathrm{Ic}}$ data. The first observation is that Eq. (9) is only a fitting function for the data in the temperature range -100 to $+100^{\circ} \mathrm{F}$, hence it is not a true lower bound to all of the data. In the transition region, the ASME $\mathrm{K}_{\mathrm{Ic}}$ curve rises more rapidly than the tolerance bound to the master curve. The deviation starts at $\mathrm{T}-\mathrm{RT}_{\mathrm{NDT}}$ above $25^{\circ} \mathrm{C}$. On the other hand, this is the region where almost no $\mathrm{K}_{\mathrm{Ic}}$ data were available to justify the curve shape. Thus, the shape of the ASME curve at T - RT $T_{\mathrm{NDT}}$ above $25^{\circ} \mathrm{C}$ reflects a postulated shape, while the master curve concept has been experimentally proven to describe an unsubjective scatter of elastic-plastic-based fracture toughness values in the transition region. In this discussion however, the caution regarding the necessity for using only valid $\mathrm{K}_{\mathbf{c}}$ data is relaxed by applying the master curve based on $\mathrm{K}_{\mathrm{fc}}$ data to describe the scatter of $\mathrm{K}_{\mathrm{Ic}}$ data of the same material and also the total $\mathrm{K}_{\mathrm{tc}}$ database. The specific advantage of the present results is that the master curve was developed from PCVN specimens.

\section{SUBSIZE PRECRACKED CHARPY DATA}

The fracture toughness tests with 4.8-mm-thick specimens of HSST Plate 02 at $-50^{\circ} \mathrm{C}$ exhibit some disparities in results (Table 1 ). The median of twelve $\mathrm{K}_{\mathrm{Jc}}$ data of $4.8 \times 4.8 \times 27 \mathrm{~mm}$ specimens is $96.4 \mathrm{MPa} \sqrt{\mathrm{m}}$, which yields $\mathrm{T}_{100}=-21^{\circ} \mathrm{C}$. The median of eight $\mathrm{K}_{\mathrm{Jc}}$ data of $4.8 \times 10 \times 55 \mathrm{~mm}$ specimens is $75.8 \mathrm{MPa} \sqrt{\mathrm{m}}$, which yields $\mathrm{T}_{100}=+1^{\circ} \mathrm{C}$. Figure 3 compares the median $\mathrm{K}_{\mathrm{sc}}$ values of different specimens tested at $-50^{\circ} \mathrm{C}$. The $\mathrm{K}_{\mathrm{Jc}(\mathrm{med})}$ values are plotted against thickness of specimens, $\mathrm{B}_{(\mathrm{x})}$, relative to $1 \mathrm{~T}$ compact specimen thickness, $\mathrm{B}_{(1 \mathrm{~T})}$. The median $\mathrm{K}_{\mathrm{Jc}}$ value of $71.9 \mathrm{MPa} \sqrt{\mathrm{m}}$ derived from analysis of IT specimens [6] is used as a reference point to plot as a solid line the median $\mathrm{K}_{\mathrm{Jc}}$ trend

${ }^{3}$ In this case, $\mathrm{T}_{100}=-25^{\circ} \mathrm{C}, \mathrm{RT}_{\mathrm{NDT}}=-18^{\circ} \mathrm{C}\left(0^{\circ} \mathrm{F}\right)$, and $\Delta \mathrm{T}_{100}=7^{\circ} \mathrm{C}$. 


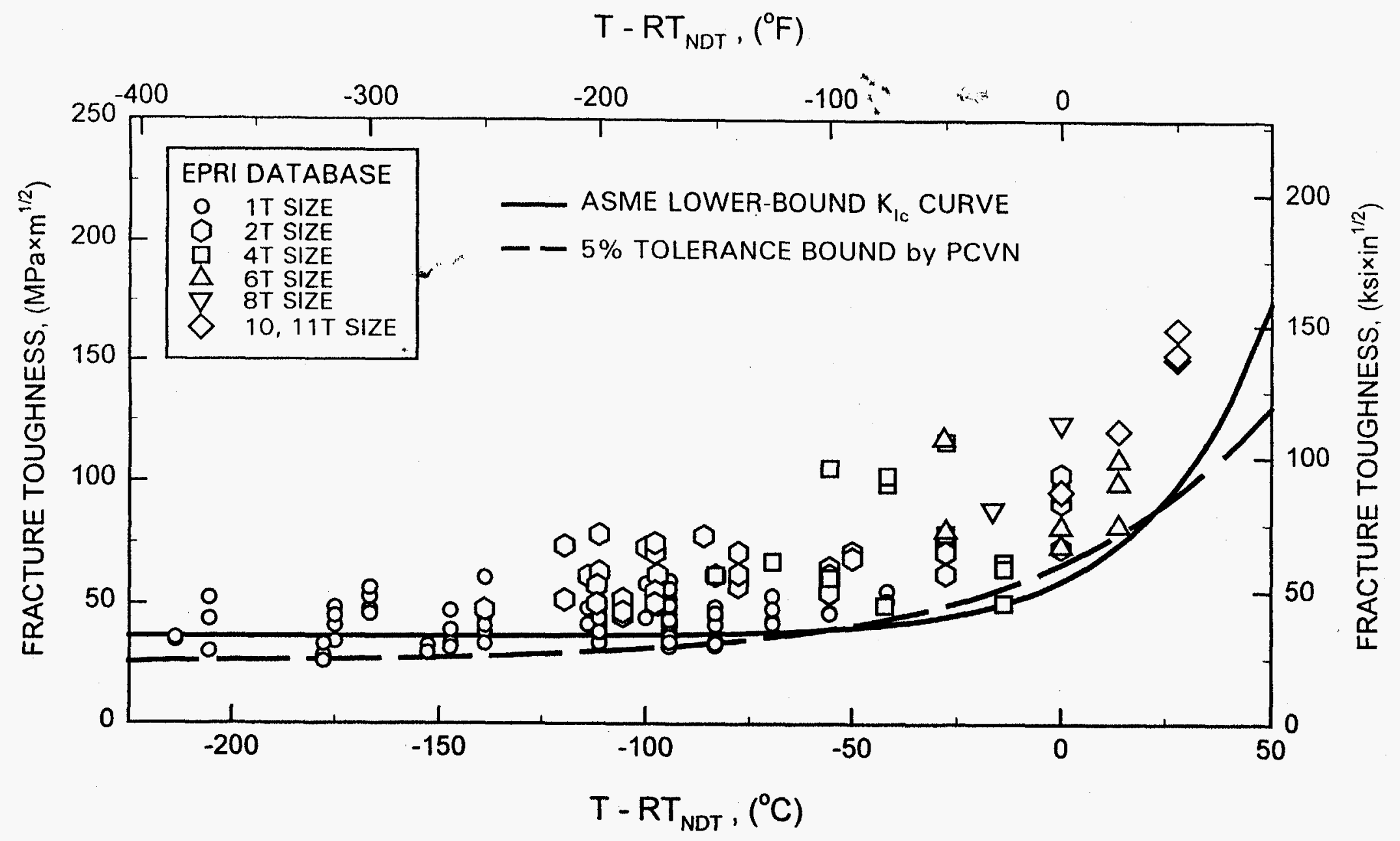

FIG. 2--Comparison of the $\mathrm{K}_{\mathrm{Ic}}$ EPRI database and ASME lower-bound curve relative to the $5 \%$ margin-adjusted tolerance bound curve derived by testing of several PCVN specimens of HSST Plate 02. 
prediction according to the weakest-link size adjustment model by Eq. (5) covering the range of thicknesses studied. In addition to the specimens of the present study, the median fracture toughness of $2 \mathrm{~T}$ compact specimens tested by Westinghouse [4] at $-46^{\circ} \mathrm{C}$ and $0.2 \mathrm{~T}$ compact specimens tested by ORNL [9] at $-50^{\circ} \mathrm{C}$ are also presented on Fig. 3. As discussed earlier, PCVN data and 2T compact specimen data follow the size adjustment model. The $4.8 \times 4.8 \times 27 \mathrm{~mm}$ specimen data also show good agreement with the weakest-link size adjustment model of Eq. 5 .

However, the median data point from $4.8 \times 10 \times 55 \mathrm{~mm}$ specimens fell below this model trend. The median of eight $\mathrm{K}_{\mathrm{rc}}$ data of $4.8 \times 10 \times 55 \mathrm{~mm}$ specimens is $75.8 \mathrm{MPa} \sqrt{\mathrm{m}}$, which yields $\mathrm{T}_{100}=+1^{\circ} \mathrm{C}$. Results of six $0.2 \mathrm{~T}$ compact specimens $(5 \mathrm{~mm}$ thick) tested at the same temperature [9] almost reproduce data of $4.8 \times 10 \times 55 \mathrm{~mm}$ three-point bend specimens. The median $\mathrm{K}_{\mathrm{c}}$ of $0.2 \mathrm{~T} \mathrm{C}(\mathrm{T})$ is $73.8 \mathrm{MPa} \sqrt{\mathrm{m}}$, which yields $T_{100}=+2{ }^{\circ} \mathrm{C}$. These two types of specimens have one common parameter - the ratio of width (W) to the thickness (B) is equal to 2 , while the PCVN and its smaller equivalent $4.8 \times 4.8 \times 27 \mathrm{~mm}$ specimens have $\mathrm{W} / \mathrm{B}$ equal to 1 .

$2 \times$

The disparity in results for the three different specimens sizes is not evident from the Weibull probability plots of Fig. 4. For all three specimen sizes, the scatter of data follows the same Weibull slope of 4, denoted by the solid lines in Fig. 4. Square points in Fig. $4 \mathrm{a}$ are the data which exceeded the constraint limit set by Eq. (3). Load-displacement curves of three-point bend specimens were normalized into so-called "key curves" using limit load expressions described in Ref. [10] and these key curves are compared in Fig. 5. In addition, the key curves from 1T compact specimens tested at $-40^{\circ} \mathrm{C}[5]$ are also presented in Fig. 5. Each type of specimen had exhibited different levels of plastic deformation prior to cleavage; however, all three specimen designs tend to have the same deformation characteristics as indicated by the key curve data of Fig. 5. As stated, this suggests that stress-strain conditions in the plane of the crack are comparable for all three-point bend specimens. The key curves of $1 \mathrm{~T}$ compact specimens also followed the same trend, but cleavage in these considerably larger specimens occurred at significantly lower plastic deformation.

Additional tests of ten $4.8 \times 10 \times 55 \mathrm{~mm}$ specimens were performed at $-30^{\circ} \mathrm{C}$; from analysis of these data, the reference fracture toughness temperature, $T_{100}$, was determined as $-15^{\circ} \mathrm{C}$ (Table 1), confirming that the $\mathrm{K}_{\mathrm{Jc}(\mathrm{mer})}$ value is below the size-adjustment value predicted by Eq. (5) from IT compact specimen data.

Analysis of 4.8-mm-thick specimens studied here suggests that the mathematical expression for weakest-link theory size adjustment by Eq. (5) may not apply at small thicknesses. Further investigations need to be performed to develop a unique size adjustment model for such small thicknesses. 


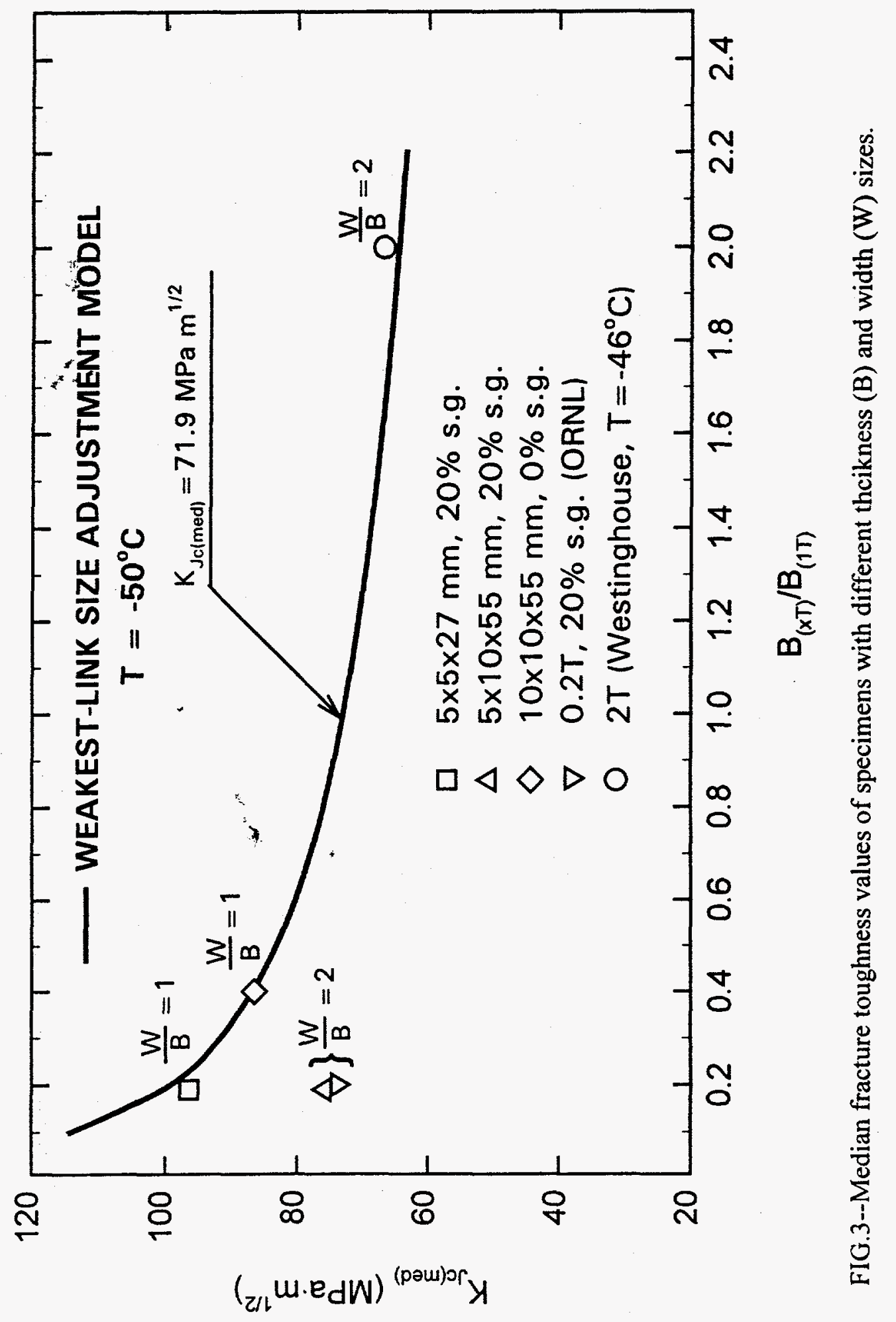




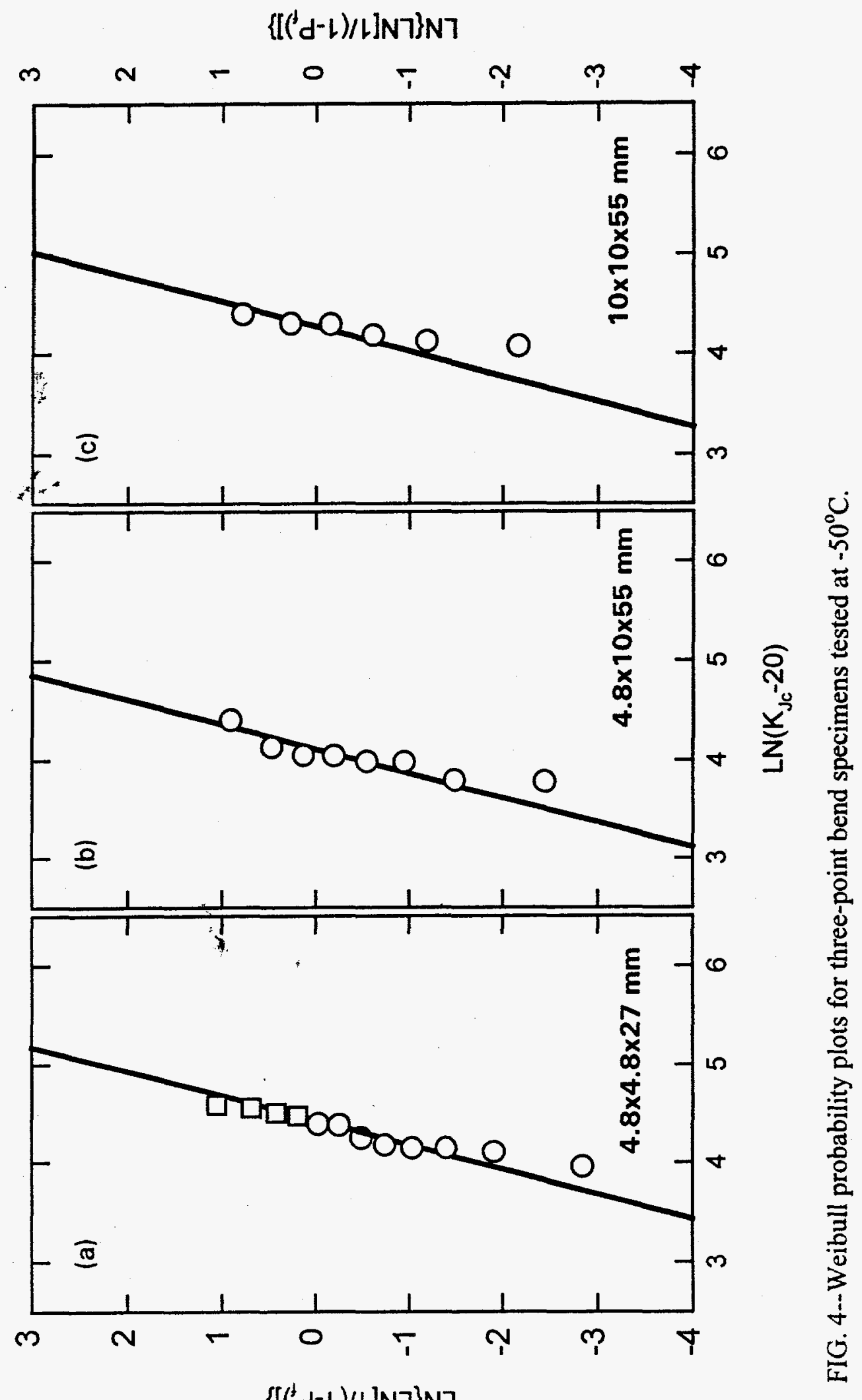




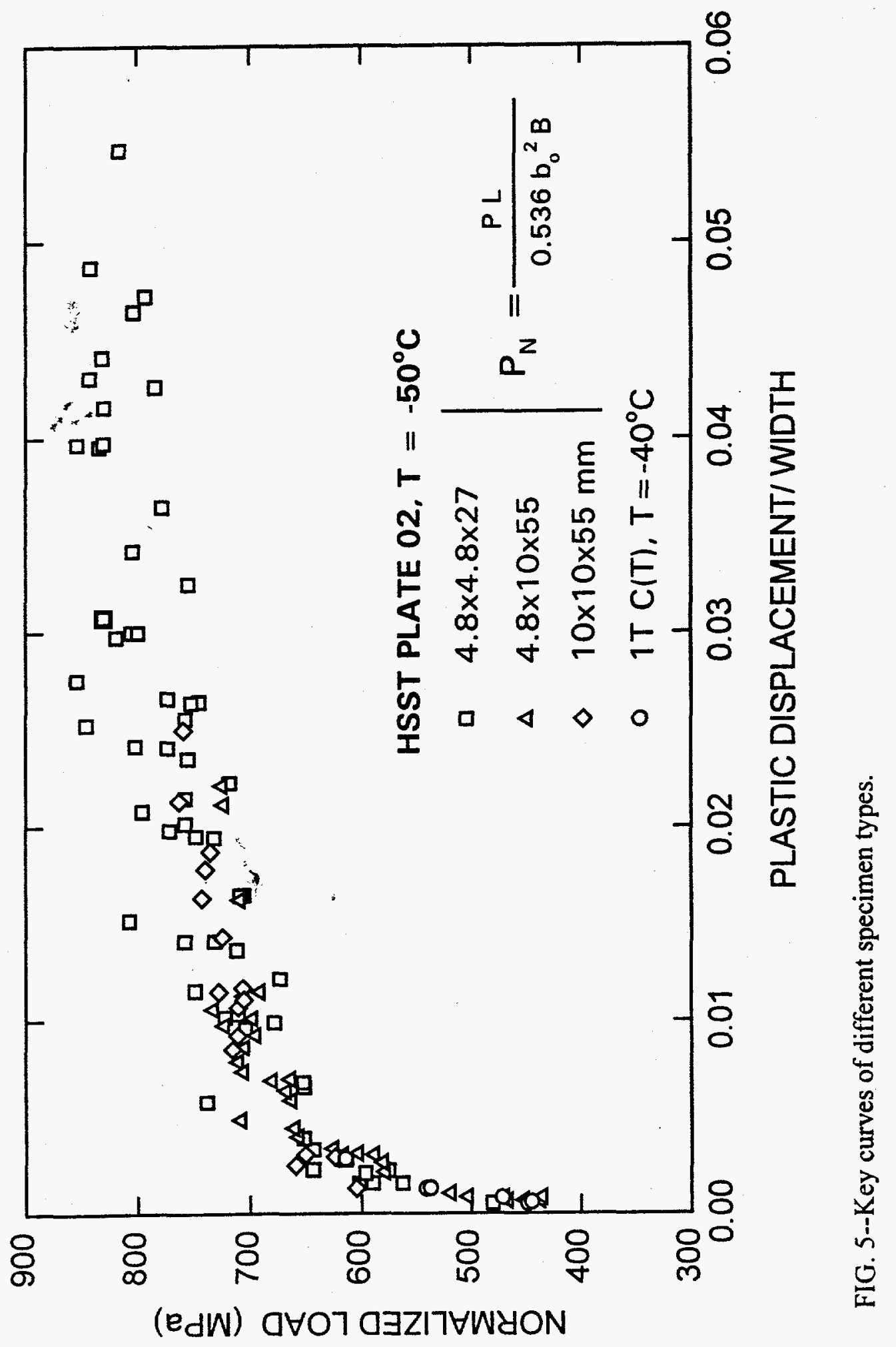




\section{SUMMARY AND CONCLUSIONS}

The applicability of small specimens to characterize the fracture toughness of RPV steels has been examined by three-point slow bend testing of precracked CVN and smaller size specimens. Weibull statistical concepts were applied to analyze $\mathrm{K}_{\mathrm{Jc}}$ values and the master curve approach was used to describe the temperature dependence of fracture toughness in the transition region.

It is shown that the master curve derived from the testing of several PCVN specimens of HSST Plate 02 represents very well the large linear-elastic $\mathrm{K}_{\mathrm{Ic}}$ database [adjusted to $1 \mathrm{~T} \mathrm{C(T)} \mathrm{size]} \mathrm{accumulated} \mathrm{by} \mathrm{the} \mathrm{testing} \mathrm{of} \mathrm{massive} \mathrm{specimens} \mathrm{needed} \mathrm{for} \mathrm{K}_{\mathrm{Ic}}$ validity. Also the $5 \%$ margin-adjusted tolerance bound of the master curve describes successfully the lower bound of scatter in $\mathrm{K}_{\mathrm{tc}}$ of this same material.

The 4.8-mm-thick specimens exhibited some disparities in results relative to the current weakest-link size adjustment predictions, indicating that the current mathematical expresssion for weakest-link theory size adjustment may need some evaluation for such small thicknesses. The current results suggest that ratio of width to thickness becomes a vital parameter in size adjustment modeling for specimens with small thickness. Further investigation is needed to develop a unique size adjustment model for small thicknesses.

\section{ACKNOWLEDGMENTS}

This research is sponsored by the Office of Nuclear Regulatory Research, U.S. Nuclear Regulatory Commission, under Interagency Agreement DOE 1886-N109-8L with the U.S. Department of Energy under Contract DE-AC05-960R22464 with Lockheed Martin Energy Research Corporation. The authors would like to thank Ronald L. Swain for testing, David J. Alexander for peer review, and Julia L. Bishop for preparation of the manuscript.

\section{REFERENCES}

[1] Wallin, $\mathrm{K}$., "The Size Effect in $\mathrm{K}_{\mathrm{Ic}}$ Results," Engineering Fracture Mechanics, Vol. 22, No.1, pp.149-163, 1985.

[2] Wallin, $\mathrm{K}$. , "The Scatter in $\mathrm{K}_{\mathrm{rc}}$-Results," Engineering Fracture Mechanics, Vol. 19, No.6, pp.1085-1093, 1984.

[3] "Test Method for the Determination of Reference Temperature, $T_{0}$, for Ferritic Steels in the Transition Range," Proposed ASTM Test Practice, Draft 12, ASTM Task Group E08.08.03, American Society for Testing and Materials, West Conshohocken, Pa., 1996.

[4] Marston, T. U., Ed., Flow Evaluation Procedures: Background and Application of ASME Section XI Appendix A, EPRI NP-719-SR, Electric Power Research Institute, Palo Alto, Calif., 1978. 
[5] McGowan, J. J., Nanstad, R. K., and Thoms, K. R, Characterization of Irradiated Current-Practice Welds and A533 Grade B Class 1 Plate for Nuclear Pressure Vessel Service, NUREG/CR-4880, Vol. 1 (ORNL-6484/V1), Oak Ridge National Laboratory, Oak Ridge, Tenn., 1988.

[6] Sokolov, M. A., Wallin, K., McCabe, D. E., "Application of Small Specimens to Fracture Mechanics Characterization of Irradiated Pressure Vessel Steels," Fatigue and Fracture Mechanics: 28th Volume, ASTM STP 1231, J. H. Underwood, B. D. MacDonald, and M. R. Mitchell, Eds., American Society for Testing and Materials, West Conshohocken, Pa., to be published.

[7] Sokolov, M. A., "Statistical Analysis of the ASME $\mathrm{K}_{\mathrm{k}}$ Database," Journal of Pressure Vessel Technology, Transactions of the ASME, Vol. 120, February 1998.

[8] Nanstad, R. K., Keeney, J. A., and McCabe, D. E., Preliminary Review of the Bases for the $K_{I c}$ Curve in the ASME Code, ORNL/NRC/LTR-93/15, Oak Ridge National Laboratory, Oak Ridge, Tenn., 1993.

[9] Alexander, D. J., unpublished work, Oak Ridge National Laboratory, Oak Ridge, Tenn., 1996.

[10] :Kumar, V., German, M. D., and Shih, C. F., An Engineering Approach for Elastic-Plastic Fracture Analysis, EPRI-NP-1931, Electric Power Research Institute, Palo Alto, Calif., 1981. 